Res Publica. Revista de Historia de las Ideas Políticas ISSN-e: 1989-6115

http://dx.doi.org/10.5209/RPUB.63890

\title{
El mundo global desde Unamuno
}

\author{
Ignacio Valdés López*
}

Recibido: 13 de marzo de 2018 / Aceptado: 14 de diciembre de 2018

Resumen. La actualidad globalizada, sometida a una aceleración productora de innumerables alteraciones, está acabando con el espacio común tradicional. Las nuevas formas de organización de la comunidad establecen identidades que alteran el modo de relación. Se hace imprescindible una revisión crítica de los supuestos modernos para el establecimiento de una conceptualización adecuada a las demandas presentes. En este sentido, el trabajo de Miguel de Unamuno sirve como estímulo intelectual para desvelar las contradicciones insertas en la deriva política global.

Palabras clave: Globalización; Comunidad; Conceptualización; Conflicto dialéctico; Crítica intelectual.

\section{[en] The global World through Unamuno}

\begin{abstract}
The globalized world, subject to an acceleration that produces innumerable alterations, is putting an end to the traditional common space. New forms of community organization establish identities that alter the mode of relationship. A critical revision of modern assumptions is essential for the establishment of a conceptualization appropriate to the present demands. In this sense, the work of Miguel de Unamuno serves as an intellectual stimulus to reveal the contradictions inserted in the global political drift.
\end{abstract}

Keywords: Globalization; Community; Conceptualization; Dialectical conflict; Intellectual criticism

Sumario. 1. Introducción. 2. La crisis del espacio común. 3. La alteración de los modos de relación.

Cómo citar: Valdés López, I. (2019). El mundo global desde Unamuno (1801-1810), en Res Publica $22.1,157-170$

\section{Introducción}

El presente en continua transformación está agotando el manantial conceptual emanado de la modernidad. Los nuevos retos, debido a la pujanza de lo económico, necesitan de análisis. El camino para el establecimiento de soluciones únicamente puede venir desde el planteamiento de "problemas" como preludio para la acción. Es decir, seguir el planteamiento unamuniano en el que "problema" toma el sentido etimológico de

\footnotetext{
* UNED

nachovaldex@gmail.com
} 
proballein: echar o poner por delante. El término se identifica con proyecto, con la emergencia de la acción práctica a través de la idea ${ }^{1}$. La aparente inmutabilidad en la deriva económica y política contemporánea oculta contradicciones a desvelar por medio de la problematización crítica. La nueva forma organizativa es, por su propia naturaleza, porosa y mutable, pues carece de centro de poder en sentido tradicional y no se erige desde el establecimiento de fronteras por lo que nos encontramos ante un modelo que ejerce su dominio desde la descentralización y la desterritorialización; el campo de operaciones carece de limitaciones y las identidades subsiguientes son híbridas y maleables ${ }^{2}$. Se requiere en consecuencia una posibilidad reflexiva que incite el desarrollo de una conceptualización para clasificar lo acontecido. La conceptualización que expresa el comportamiento racional está cargada por la época histórica en la que se ha desarrollado ${ }^{3} \mathrm{y}$, por este motivo, es forzoso explorar las alteraciones presentes. El encuentro entre posicionamientos, a través del conflicto dialéctico, desvela lo latente bajo el orden vigente. A modo de estímulo, el enfrentamiento intelectivo habilita la problematización del presente y desnuda la conflictividad inherente a lo político.

Es curioso lo que pasa con las ideas. Tenemos en el espíritu muchas veces una tropa de ellas que se arrastran vegetativamente en la oscuridad, mustias, incompletas, sin conocerse unas a otras y huyéndose mutuamente. Porque en la oscuridad las ideas, lo mismo que los hombres, se tienen miedo. [...] Pero he aquí que de pronto entra una idea nueva y luminosa $[\ldots]$ y al verle las otras $[\ldots]$ recobran plena vida ${ }^{4}$.

El intelectual está capacitado, por su posicionamiento crítico, para la ruptura con el reduccionismo y la invariabilidad de pensamiento que obstruye las posibilidades intelectivas ${ }^{5}$. Extirpando lo superfluo se hace real la ocasión para el cambio del presente partiendo de su análisis y proyección de futuro. Además, en el ámbito capitalista se encuentra el lugar idóneo para el desarrollo de esta tarea crítica, pues cualquier ataque contra la intelectualidad se dirige, finalmente, contra el orden económico caracterizado por la ausencia de restricciones; por tanto, el orden capitalista es incapaz de dominar a la intelectualidad ${ }^{6}$. La reflexión unamuniana, emblema del intelectual comprometido, se torna una eficaz herramienta con uso en la actualidad; pues, sin lugar a dudas, el bilbaíno fue poseedor de una mirada inquisitiva que se sumergió en la esencialidad de su tiempo.

\section{La crisis del espacio común}

Ni la democracia ni los Estados occidentales actuales son formas de organización naturales o intuitivas ${ }^{7}$; son producto de un largo desarrollo. Es imprescindible la

\footnotetext{
M. Unamuno, Cómo se hace una novela, Madrid, Salvat Editores en colaboración con Alianza Editorial, 1969, p. 177.

M. Hardt y A. Negri, Imperio, Barcelona, Paidós Surcos 3, 2005, p. 14.

J. A. Schumpeter, Capitalismo, socialismo y democracia. Volumen 1, Barcelona, Página indómita, 2015, p. 332.

4 M. Unamuno, Sobre la europeización (arbitrariedades), en Obras Completas, VII, Madrid, Ediciones de la fundación José Antonio de Castro, 2007, p. 1008.

E. W. Said, Representaciones del intelectual, Barcelona, Debate, 2016, p. 13.

J. A. Schumpeter, op. cit., pp. 278-279.

7 R. Herrera, Adiós al orden. Una historia sobre la deriva del Estado europeo hasta nuestros días, La Coruña, Espacio Cultura Editores, 2009, p. 12.
} 
supervisión de estas formas de organización que, si bien no eliminan la injusticia connatural de todo sistema político, reconocen la existencia de voces discordantes ${ }^{8}$. La particularidad de lo social no puede enmarcarse de manera perfecta en ningún modelo9; es un absoluto inalcanzable. De hecho, la comunidad implica una ruptura con la subjetividad, con lo individual. Lo común significa arrojarse a lo ajeno, a la alteridad con la que se comparte un espacio a configurar. Lo político, por tanto, se da siempre en los otros, es una no-cosa constituida por la ausencia y por su carácter imposible. Lo propio se pierde, se expulsa al vacío para reconfigurarse en su pérdida bajo la forma del espacio político ${ }^{10}$. Se produce el enfrentamiento agónico entre contrarios, el reflejo de la realidad existencial del ser humano patente en este espacio compartido. Lo político, como producción humana, contiene esencialmente este carácter oscilante entre lo convenido y lo natural ${ }^{11}$.

¿Contradicción? ¡Ya lo creo! ¡La de mi corazón, que dice sí, y mi cabeza, que dice no! Contradicción, naturalmente. [...] ¡Contradicción!, ¡naturalmente! Como que sólo vivimos de contradicciones, y por ellas; como que la vida es tragedia, y la tragedia es perpetua lucha, sin victoria ni esperanza de ella; es contradicción ${ }^{12}$.

La discordancia se encuentra en lo comunitario, es un elemento fundamental de su propio ser expresado en las relaciones entre los individuos del conjunto. De ahí la conflictividad, la fricción inserta en lo común que invita a la acción práctica.

Mi amor a la muchedumbre es lo que me lleva a huir de ella. Al huirla, la voy buscando. No me llames misántropo. Los misántropos buscan la sociedad y el trato de las gentes; las necesitan para nutrir su odio o su desdén hacia ellas. El amor puede vivir de recuerdos y de esperanzas; el odio necesita realidades presentes ${ }^{13}$.

Lo político, debido a su propia configuración, se ve abocado al nihilismo por su renuncia a la posibilidad de incorporar el Bien, el Uno o la Justica en modo absoluto ${ }^{14}$. Se introduce un elemento representativo de la contemporaneidad bajo la forma de la nada-en-común ofrecida por lo comunitario ${ }^{15}$. Estas limitaciones, asumidas como adecuadas para lo político, se ven rebasadas por el desarrollo globalizador caracterizado por la aceleración ${ }^{16}$. El antiguo horizonte de expectativa, representado por las esperanzas depositadas en un modelo configurado por la experiencia compartida, ha estallado bajo el empuje de la novedad. Las mutaciones se han multiplicado haciendo estéril la conceptualización de la que surgían los valores, planteamientos y direccionamientos comunes. La soberanía moderna, ejecutiva en vinculación con un

R. Herrera, Un largo día. Globalización y crisis política, Murcia, Tres Fronteras ediciones, 2008, p. 25.

J. L. Villacañas Berlanga, Populismo, Madrid, La Huerta Grande Editorial, 2015, p. 84.

10 R. Esposito, Comunidad, inmunidad y biopolitica, España, Herder, 2009, pp. 63-65.

11 R. Esposito, Diez pensamientos acerca de la política, Buenos Aires, Fondo de cultura económica, 2012, p. 58.

12 M. Unamuno, Del sentimiento trágico de la vida en los hombres y en los pueblos, Madrid, Alianza Editorial, 1997 , p. 33.

13 M. Unamuno, Soledad, en Obras Completas, VIII, Madrid, Ediciones de la fundación José Antonio de Castro, 2007, p. 779.

14 R. Esposito, Comunidad, inmunidad y biopolitica, op. cit., p. 61.

15 Ibidem, p. 64.

16 R. Herrera, Adiós al orden. Una historia sobre la deriva del Estado europeo hasta nuestros días, op. cit., p. 24. 
centro operativo, ha sido desplazada, pues el capital opera en el plano inmanente sin necesidad de ningún foco particular. El funcionamiento desterritorializador e inmanente del capital se muestra de la siguiente manera: destruye las culturas tradicionales y las organizaciones sociales, elimina todo sistema jerárquico previo y se rige por leyes volubles y cambiantes; el capital no necesita de ningún poder trascendente para ejercer su dominio ${ }^{17}$. Esto ha provocado la fractura de las categorías tradicionales y la pérdida de sentido para una comunidad en la que se han extraviado los referentes pretéritos. Con todo, el proceso capitalista está destruyendo su propia estructura institucional en virtud de su propia naturaleza ${ }^{18}$. La globalización, al socavar las estructuras propias de explotación y control, comprende en sí los elementos para la liberación de la multitud ${ }^{19}$. La cuestión se encuentra en el hecho de que las luchas sociales en el nuevo orden mundial se han mantenido clausuradas en el ámbito local, aunque, de manera evidente, están conectadas por el hecho de tocar problemas globales y enfrentarse con la organización biopolítica al plantear nuevos modelos de organización vital. La ausencia de un rival común y, sobre todo, que no exista una adecuada conceptualización que permita la comunicación entre estos puntos de resistencia atomizados, hace que no se puedan traspasar los límites de lo particular ${ }^{20}$. Con todo, la relación establecida entre el nuevo orden mundial y la multitud es de carácter dicotómico, pues la multitud contiene la fuerza productiva del mundo social y tiene la posibilidad de revertir o alterar situaciones problemáticas derivadas del modelo de organización presente. De este modo, resulta urgente la toma de conciencia sobre un nuevo modelo que encierra en su interior las soluciones a las desigualdades generadas. Desde el ámbito local, el de los Estados-nación, no es posible emprender la marcha para modificar las problemáticas vigentes. La cuestión se plantea en relación a la indefensión experimentada por los actores implicados en el proceso. Tradicionalmente, la gestión económica se ha relacionado con el derecho como garantía de protección jurídica ${ }^{21}$. Sin embargo, la actualidad ofrece un referente que fractura la configuración jurídico-legal anteriormente preservada en el Estado. Es un hecho que la decadencia de los Estados-nación implica un proceso estructural que se deja sentir en la menguante influencia de su estructura jurídico-político. Es por esto que algunos aspectos de las desigualdades sistémicas se han hecho más acusadas y peligrosas para el conjunto ${ }^{22}$.

La expansión de los conglomerados empresariales transnacionales ha desembocado en una situación de desamparo. El escenario legal ya no ofrece garantías y el mundo globalizado, al cerrarse sobre sí mismo, evita la intromisión jurídica estatal ${ }^{23}$. Atendiendo a los principales componentes de la acción social, se hace imprescindible el estudio de los elementos económicos adheridos en lo político. El ámbito de lo social, como espacio político, debe establecer vinculaciones con lo pecuniario para lograr su propia supervivencia. El espacio público, que permite la interacción, se encuentra en decadencia por la convivencia de los polos opuestos de la globalización:

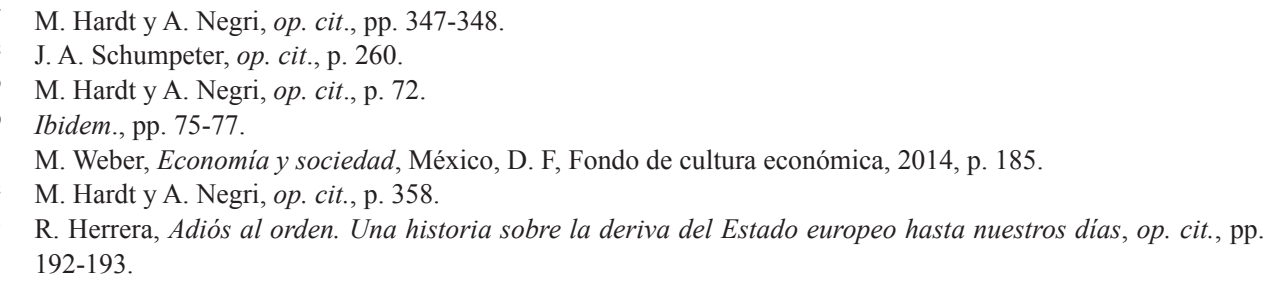


desarrollo y subdesarrollo en un único escenario ${ }^{24}$. Se instituye un entorno paralelo al jurídico que crea finalidades utilitaristas incompatibles con lo humano ${ }^{25}$. Resulta, gracias a esta dinámica, una intensificación de la racionalización de las economías lucrativas ${ }^{26}$. De hecho, el modelo globalizado actual, establecido sobre la búsqueda incesante de beneficios, exporta capital y bienes de consumo a zonas en desarrollo para conseguir mano de obra explotable. Esta persecución de material humano utilizable muestra rasgos de los procesos de colonización, pues debe subyugar la política local ${ }^{27}$. Unamuno comprendió esta tendencia y la identificó con el desprecio que la sociedad contemporánea profesa hacia todo aquello incomprensible por estar alejado de la pragmática capitalista:

Esto de desdeñar, o por lo menos fingir desdeñar lo que no podemos entender o sentir, es uno de nuestros defectos capitales, defecto que estalla cuando el tener fortuna le quita la vergüenza al hombre inculto y rudo ${ }^{28}$.

Lo político, en su vinculación con lo económico, se emancipa de la moralidad. La asepsia de la ciencia económica, que ha terminado por alcanzar a lo comunitario, se deshace de lo superfluo por el éxito comercial ${ }^{29}$. Se funda una estrategia compensatoria y adaptativa por medio de la cual se desbarata el terreno moral a favor del libre desarrollo económico; las tendencias sentimentales son superadas. Es más, el nuevo sistema global automatiza la autoridad mediante acuerdos que marcan la acción ${ }^{30}$. Este nuevo poder tiene una naturaleza biopolítica ${ }^{31}$ y se está desarrollando una novedosa teoría del valor debido a las transformaciones de un trabajo productivo cada vez menos material. Por supuesto, esta nueva teorización debe ir acompañada de una noción sobre la subjetividad ${ }^{32}$. El sujeto, gracias a esta estrategia, es capaz de crear un espacio más allá de la comunidad: un mundo económico global administrado por su propia reglamentación $^{33}$, aunque, en un primer momento, los grupos capitalistas se adapten a las distintas políticas locales buscando, en virtud de la flexibilidad de sus presupuestos, la mejor adaptada a sus intereses ${ }^{34}$. La influencia ejercida por las ciencias empíricas ha contagiado a lo social. Se admite la existencia de unas leyes invariables que, gracias al enfoque de la política hacia el rendimiento económico, devendrían en un modelo de organización más eficiente y en un reparto más justo de las riquezas ${ }^{35}$. Todo, incluso

24 M. Hardt y A. Negri, op. cit., p. 359.

25 J. L. Villacañas Berlanga, "Max Weber entre liberalismo y republicanismo", en Isegoría 33, 2005, pp. 127-141, aquí p. 130.

26 M. Weber, Economía y sociedad, op. cit., p. 196.

27 J. A. Schumpeter, op. cit., pp. 118-119.

28 M. Unamuno, Soliloquios y conversaciones, en Obras Completas, IX, Madrid, Ediciones de la fundación José Antonio Castro, 2008, p. 307.

29 M. Weber, Economía y sociedad, op. cit., p. 268.

30 M. Hardt y A. Negri, op. cit., p. 34.

${ }^{31} \quad$ Ibidem, p. 44

32 Ibidem, p. 50.

33 O. Marquard, Filosofia de la compensación. Estudios de antropología filosófica, Barcelona, Ediciones Paidós Ibérica, 2001, p. 27.

34 J. A. Schumpeter, op. cit., p. 127.

35 H. Castignani, "Distopias. Del panoptismo a la actual sociedad de la vigilancia: Hegel, Foucault, Deleuze", en Moisés González García y Rafael Herrera Guillén (eds.), Utopía y poder en Europa y América, Madrid, Editorial Tecnos, 2015, p. 413. 
la reflexión intelectual, se carga por una excesiva conceptualización racionalista que evita algo básico para Unamuno: la sentimentalidad.

Pero así como un conocimiento científico tiene su finalidad en los demás conocimientos, la filosofía que uno haya de abrazar tiene otra finalidad extrínseca, se refiere a nuestro destino todo, a nuestra actitud frente a la vida y al universo. Y el más trágico problema de la filosofía es el de conciliar las necesidades intelectuales con las necesidades afectivas y con las volitivas ${ }^{36}$.

El auge del capitalismo global deja de lado la realidad humana, su dimensión agónica y sentimental. La consecución de beneficio se impone sobre la vida y recursos de aquellos que no pueden participar en esta causa y, aunque el movimiento económico es hacia la gran empresa, este fenómeno va acompañado de una miseria creciente que afecta a un grupo cada vez más amplio de la población mundial ${ }^{37}$. El entramado común, relativo al ser humano real, queda relegado por resultar una variable imponderable: "Y todo ello son consecuencias del proceso económico capitalístico actual, en el que la vida de los unos es un mero medio para la conservación $\mathrm{y}$ disfrute de la vida de otros" ${ }^{\prime 38}$. Aunque, en último término, el capitalismo, con independencia de sus logros, socava las instituciones que lo amparan provocando su inevitable debilitamiento ${ }^{39}$.

El liberalismo económico clásico consideraba incomprensible la economía de mercado sin un orden moral. De este modo, la libertad quedaría garantizada por un andamiaje jurídico-legal ${ }^{40}$. Weber entendió como básica la protección jurídica, la división de poderes y la libertad individual para la promoción de la responsabilidad política ${ }^{41}$. El espacio de convivencia estatal resulta imprescindible, pues, de no darse, la comunidad quedaría subsumida en la realidad global desregularizada. Sin embargo, el Estado, tal y como está concebido, no puede responder a las demandas contemporáneas y, por este motivo, debe repensarse para adaptar el espacio común a las nuevas condiciones establecidas desde el orden mundializado. De hecho, la sociedad de control global coincide con la decadencia de los Estados-nación y con el auge de un mercado mundial que necesita de un flujo desterritorializado ${ }^{42}$. Unamuno también consideró fundamental para el desarrollo humano la presencia de un mercado liberado, aunque reglado para apoyar el progreso social y personal: "El proceso económico-social moderno, mercantil e industrial, arrancando del libre cambio trae el verdadero cosmopolitismo, la gran patria del espíritu, que del cambio se nutre, la gran Patria humana"43.

Se asiste al asalto del Estado por parte de la economía y una subjetividad mal entendida que acaba con la individualidad. Este escenario tecnificado homogenei-

M. Unamuno, Del sentimiento trágico de la vida en los hombres y en los pueblos, op. cit., p. 35.

J. A. Schumpeter, op. cit., p. 116.

38 M. Unamuno, La dignidad humana, en Obras Completas, VIII, Madrid, Ediciones de la fundación José Antonio de Castro, 2007, p. 353.

39 J. A. Schumpeter, op. cit., p. 136.

40 E. Ujaldón, La constitución de la libertad en Adam Smith, Madrid, Editorial Biblioteca Nueva, 2008 , p. 23.

41 J. L. Villacañas Berlanga, "Max Weber entre liberalismo y republicanismo”, en Isegoría 33, 2005, pp. 127-141, aquí p. 132.

42 M. Hardt y A. Negri, op. cit., p. 354.

43 M. Unamuno, La crisis del patriotismo, en Obras Completas, VIII, Madrid, Ediciones de la fundación José Antonio de Castro, 2007, p. 362. 
za todo su contenido; se marca un ciclo eternamente repetido en el que la libertad queda suspendida y, en última instancia, anulada al no ejercerse ${ }^{44}$. El mundo virtual y global ha rebasado la organización estatal, la ha vaciado de su contenido esencial haciendo imposible su gestión ${ }^{45}$. La multitud es dirigida con los instrumentos del sistema capitalista posmoderno en el ámbito biopolítico de su existencia, aunque, por otro lado, en esta misma multitud se encuentra la posibilidad para acabar con este tipo de dominio ${ }^{46}$. Esta deriva disuelve las categorías modernas de Estado, Derecho e individuo sin llegar a determinar las sustitutas. La autoridad globalizada ha desbancado las anteriores formas de soberanía para abrazar el mando biopolítico ${ }^{47}$. Ante esta desorientación, las democracias occidentales establecen un espacio de exclusión en el que las libertades se suspenden. Frente a la comunidad, acicate para que el sujeto se lance a la alteridad, se ha erigido la immunitas que libera de esta posibilidad. En este contexto de dubitación la conceptualización política está incapacitada para establecer un horizonte de expectativa, la inmunización reconstruye, a costa de lo político, el ámbito de la identidad individual ${ }^{48}$. En la anterior sociedad disciplinaria se creaban identidades vinculadas a los distintos espacios de gestión de lo público; sin embargo, en la sociedad de control actual la subjetividad es híbrida y no se vincula con ningún emplazamiento determinado. Todas las instituciones entrecruzan su influencia para establecer un modelo de subjetividad afín a la lógica del capital ${ }^{49}$; el dinero es una herramienta de control de carácter absoluto ${ }^{50}$.

\section{La alteración de los modos de relación}

El tiempo gozne actual está modificando los modelos de relación interpersonal. La tendencia global, fundada sobre el acelerado desarrollo de las tecnologías de la información y la comunicación, ha marcado un aislamiento e independencia idiosincrásicos de la comunicación virtual. Se ha forjado una vinculación global e inmediata que crea nuevos nuevas costumbres y modos de conexión. El manejo de la comunicación, la cultura y la educación son elementos íntimamente vinculados con el nuevo modelo de poder que se ha desarrollado ${ }^{51}$.

El trabajo, transformado por el espíritu capitalista en beneficio para la comunidad, permitía contribuir al bien común ${ }^{52}$. Sin embargo, el desequilibrio resultó uno de los rasgos del sistema; el éxito individual se constituye sobre el fracaso ajeno ${ }^{53}$. La necesidad de financiación termina por vincular la política a lo económico ${ }^{54}$. $\mathrm{La}$ realidad laboral ha sido totalmente devaluada, pues las políticas sociales y la legislación laboral que no abrazan la flexibilidad y movilidad provocan el castigo a

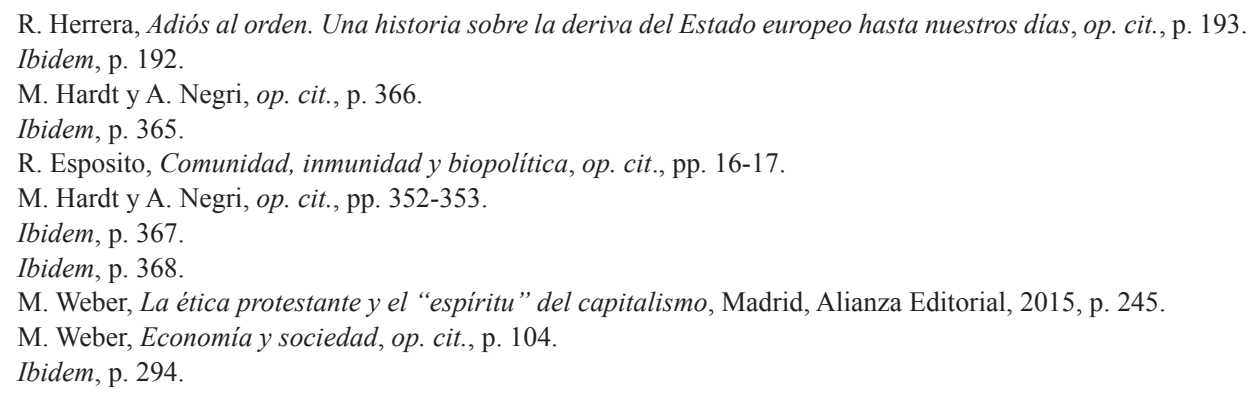


esas regiones ${ }^{55}$. Es más, el paro y la pobreza no serán elementos a eliminar por la evolución capitalista, pues el avance del desempleo es característico tras los cambios revolucionarios como al que estamos asistiendo ${ }^{56}$. Este proceso aleja la gestión de lo social, los mecanismos empleados para la dirección comunitaria terminan por transformarse en algo desconocido. Lo político se encadena a la rentabilidad dejando atrás la dimensión social propia de la comunidad. Esta disposición, debido a su propia configuración y las crisis cíclicas, está abocada a la emergencia populista debido al deficiente funcionamiento constitucional. Se activa, en los momentos de conflicto, el sentimiento de pertenencia al pueblo que permite la aparición de estas políticas vinculadas a un ambiente de decepción ${ }^{57}$.

Los Estados democráticos pretenden aunar la dimensión social y su financiación; el dinero permite la cuantificación en todo tipo de relación ${ }^{58}$. En un sentido radical, la economía podría convertirse en un ingrediente disponible para nivelar las ambigüedades del sistema. La cuestión se encuentra en el proceso global, pues se han rebasado fronteras y se necesitaría de una acción universal para paliar estas dificultades. La creencia en la tendencia a la autorregulación de los mercados para encontrar un equilibrio acaba por desbaratarse ${ }^{59}$. De hecho, la inestabilidad laboral y sus consecuencias en sociedad se convierten en la pauta del capitalismo desregularizado y del desarrollo tecnológico ${ }^{60}$.

El pathos tradicional desaparece en este nuevo modelo productivo que fomenta la movilidad y la desintegración del núcleo familiar. El desarrollo de este ideal social dirigido a la acumulación de capital ha orientado la economía y las relaciones interpersonales hacia un mundo globalizado. Este panorama hace muy complicada la ordenación y restricción de los mercados desde un marco jurídico-legal, pues, a decir verdad, las organizaciones estatales son rebasadas por esta circunstancia. La globalización ya está operando cambios en el derecho internacional y nacional ${ }^{61}$. La capacidad de juicio y de decisión personal son afectadas por la pseudoinvidualidad imperante en la contemporaneidad. De manera evidente, la deriva política se ve influida por esta situación ${ }^{62}$.

Aunque la novedad se encuentra en lo económico, el horizonte de expectativa se ha cargado políticamente. Por este motivo, se demanda una conceptualización adecuada para la diferenciación de los nuevos actores sociales y paradigmas asociados. La contemporaneidad desglosada de la modernidad ha dejado de lado el provenir por el porvenir. En la actualidad operan, con indiferencia a la tradición, las ciencias empíricas, la técnica, la economía y los medios de comunicación ${ }^{63}$. Se impone, como estrategia adaptativa compensatoria, la consideración para con el provenir, pues lo acostumbrado puede convertirse en apoyo para esta incesante transformación ${ }^{64}$. Así, debería realizarse una revisión de los fundamentos modernos en correspondencia

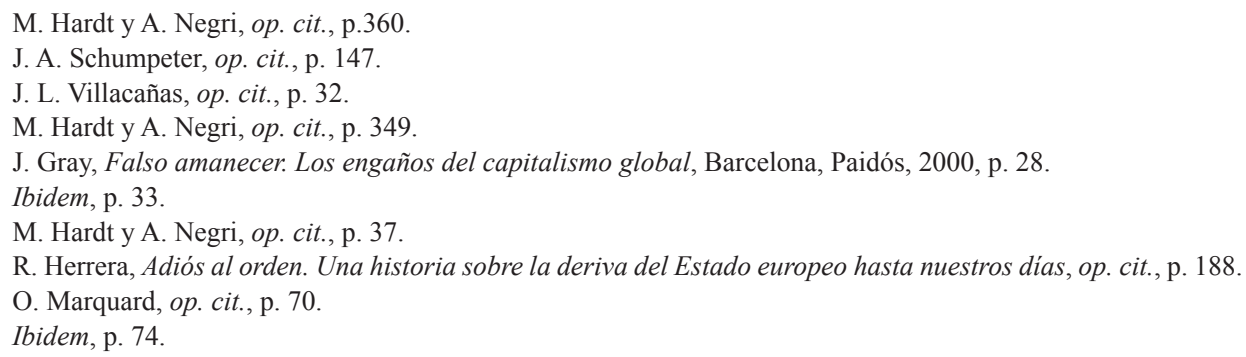


con la política y la economía para su reformulación y utilización en el presente. Es importante centrar el análisis en la novedad establecida constantemente desde el fenómeno de la destrucción creadora ${ }^{65}$.

Más allá del componente social, ha sido lo económico lo que ha abierto nuevas vías de comunicación entre nacionalidades y comunidades. El modelo de conexión anterior ha sido sustituido por la competencia y el pragmatismo. La configuración esencial de lo humano, apoyado en el espacio político, se ha relegado por la entrega a la organización fiduciaria. La interdependencia se aleja de lo cultural para abrazar el rendimiento, deja atrás la ética que regula la acción práctica ${ }^{66}$. De esta manera, la moral se ve apremiada por la banalización y rebaja generada por el nuevo canon sociopolítico ${ }^{67}$. El pensamiento económico global únicamente es afín a aquello que continúa alimentando su maquinaría y está caracterizado por un carácter objetivo apegado a lo material. No obstante, la evidente mejora de la vida producida por el capitalismo se orienta de manera primordial al ámbito del ocio evitando así que la masa popular pueda elaborar por sí misma opiniones ${ }^{68}$.

Los Estados Unidos se han convertido en el arquetipo del nuevo modelo económico global. Se podría hablar de un nuevo constructo histórico en busca de un paradigma utópico imperial dirigido a la consolidación de un tipo idealizado. De esta manera, la destrucción de lo ajeno por medio de la fagocitación que posibilita el mercado global queda justificada ${ }^{69}$. No obstante, esta deriva ha creado profundas desigualdades que afectan a los propios Estados Unidos por la merma de la cohesión social ${ }^{70}$. En este sentido, el radicalismo teocrático americano ha supuesto un desequilibrio en el orden mundial ${ }^{71}$ al imponer en un contexto absoluto sus políticas de control migratorio y seguridad ${ }^{72}$. Sin embargo, esta noción imperial tiene características novedosas, aunque comparta con el orden imperial clásico la suspensión de la historia para presentar un orden presumido como permanente, eterno y necesario, apoyado en el uso de conceptos clásicos como el de "guerra justa" aunque resulta tentador sostener la tesis sobre el dominio estadounidense, el nuevo orden global no tiene un poder centralizado debido a la caída de la influencia de los Estados-nación y la porosidad de las antiguas fronteras ante el empuje sin límites del capital ${ }^{74}$ apoyado por la intervención internacional consensuada de actores supranacionales; se han desarrollado un derecho y una justicia virtuales que ya se están aplicando $^{75}$. Todo se pospone por lo económico, de aquí surge el alimento que posibilita este dominio global por el que intentan competir inútilmente la práctica totalidad de Estados. Las denuncias ante las desigualdades enarboladas por las democracias oc-

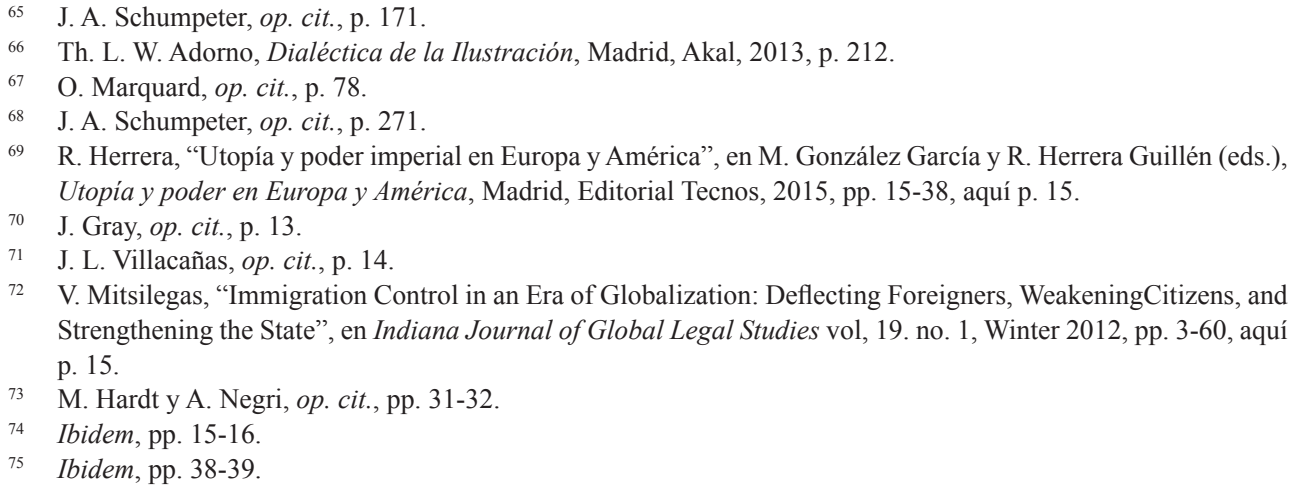


cidentales adquieren un carácter absurdo traducido en políticas globales inoperantes. El trasfondo radical es el de la lucha feroz por el dominio que resulta contradictorio con la posibilidad de enmendar la situación ${ }^{76}$. Este desvío, que socava los valores fundamentales de lo comunitario, brota del capitalismo de empresa inserto a todos los niveles engendrando rivalidad ${ }^{77}$.

Conocidísima es la doctrina que en la llamada jerarquía de los fenómenos sociales coloca a los económicos como de base y fundamental primero de los demás, por ser al organismo social lo que las funciones nutritivas al individual. [...] La estimación del mero valor de cambio aplicada al trabajo humano, y al hombre mismo por lo tanto convertido en mera mercancía, es el carácter más odioso del régimen económico-social que padecemos. Y tal estimación se extiende a la moral, a la literatura, a la ciencia, al arte, produciendo el más abyecto e infecundo mandarinismo, el verdadero materialismo mercantilista. La personalidad humana se mide con este famoso valor de cambio ${ }^{78}$.

Los conglomerados empresariales han impuesto su orientación. Como resultado, aparecen nuevos espacios totalmente ajenos a la reflexión social ${ }^{79}$ que, por añadidura, se aprovechan de las infraestructuras estatales ${ }^{80}$. Las empresas trasnacionales establecen la red conectiva de este mundo biopolítico para estructurar y articular los territorios y poblaciones ${ }^{81}$. Este modelo fundamentado en la gran empresa se ha convertido en el principal impulso para el capitalismo globalizado, es lo que permite su avance e imposición ${ }^{82}$, aunque, en definitiva, este desarrollo no ha redundado en un progreso moral o una mayor felicidad ${ }^{83}$. El orden, establecido por demanda antropológica sobre una zona determinada, ha perdido su sentido por la ruptura del espacio tradicional: el Estado ${ }^{84}$. Los modos de convivencia son perjudicados por la globalización a pesar del mantenimiento de los antagonismos propios de la fundación del Derecho por medio de la limitación del espacio; verbigracia, la oposición norte-sur; que no es más que un concepto para homogeneizar y unificar el proceso capitalista, aunque en su seno también se muestre la existencia de una oposición ${ }^{85}$. La falta de certezas absolutiza lo perecedero, no hay respaldo para la construcción de un horizonte de expectativa ${ }^{86}$. Asistimos a una crisis identitaria por el colapso categorial moderno, surgen nuevas identidades colectivas e individuales en conflicto con las anteriores. El derivado de los mercados, el consumidor, se convierte en nuevo agente

\footnotetext{
76 Th. Adorno, op. cit., p. 218.

77 H. Castignani, op. cit., p. 418.

78 M. Unamuno, La dignidad humana, op. cit., pp. 349-350.

79 J. Velázquez Delgado, "La férrea voluntad utópica de la modernidad en la rebelión de los indignados", en M. González García y R. Herrera Guillén (eds.), Utopía y poder en Europa y América, Madrid, Editorial Tecnos, 2015, pp. 319-349, aquí p. 323.

80 A. Badiou, Nuestro mal viene de más lejos, Madrid, Clave intelectual, 2016, p. 38.

${ }^{81}$ M. Hardt y A. Negri, op. cit., p. 52.

82 J. A. Schumpeter, op. cit., p. 205.

83 Ibidem, p. 244.

84 R. Herrera, Rafael, Adiós al orden. Una historia sobre la deriva del Estado europeo hasta nuestros días, op. cit., p. 27.

85 M. Hardt y A. Negri, op. cit., p. 356.

86 R. Herrera, Adiós al orden. Una historia sobre la deriva del Estado europeo hasta nuestros días, op. cit., p. $32-$ 34.
} 
político poseedor de una identidad adscrita a lo social. Se genera una mítica en torno a esta figura que consiente con la idea de que los recursos del mercado económico pueden emplearse como herramienta política ${ }^{87}$. Este establecimiento de nuevas necesidades es un rasgo connatural al capitalismo, en caso contrario se produciría una situación estacionaria hostil a los intereses financieros globales ${ }^{88}$.

El neoliberalismo ha quebrantado dimensiones públicas de carga social y económica a favor de la gestión privada. Estas políticas provocan el crecimiento de una subclase totalmente desfavorecida ${ }^{89}$. El resultado es que el desarrollo contemporáneo se está produciendo con grandes dosis de indeterminación en relación al poder, la sociedad y el resto de elementos en ligazón con el individuo. Este desenvolvimiento al margen del electorado, se da bajo la espontaneidad que no define su objetivo último. El efecto es un mercado global ilimitado y desregularizado que produce incontables problemas. Además, se incluye la competencia desmedida y la necesidad incesante de consumo como elementos que terminan por deshumanizar las relaciones. De este modo, el sistema dominante puede mantener su privilegiada posición ${ }^{90}$. Esta fórmula, en la que la organización estatal se ve obligada a aceptar flujos de capital sin ninguna regulación, provoca la injerencia privada en lo público ${ }^{91}$.

[...] nos gobierna una plutocracia anarquista. Porque los pobres, los que nada tienen que perder, según falsamente se dice, pueden y suelen ser de ordinario conservadores, mientras los ricos, los que no se hartan de que otros les ganen, pueden y suelen ser anarquistas, profundamente anarquistas. El Estado no es para ellos una arquía, un poder, una ley; mucho menos un órgano de cultura; el Estado no es para ellos más que un gendarme y una finca que explotar ${ }^{92}$.

\section{Conclusiones}

El nuevo modelo mundializado ha privilegiado el objetivo mercantil. La protección jurídico-legal del modelo liberal y democrático ha sido superada, pues, el capitalismo global ejerce una acción coactiva que se traduce en la agresividad de los mercados y la ausencia de normas. Únicamente identificando la finitud de esta estructura, asumiendo la posibilidad de su desaparición, se hace posible ponderar un sistema que, de manera objetiva, va acompañado de las mayores cotas de libertad históricas ${ }^{93}$. Implica, por tanto, contenidos positivos que pueden ser reutilizados para generar un horizonte de expectativa que consienta con un futuro ajeno a estas dificultades. El control estatal desaparece en esta lógica empresarial ${ }^{94}$, pues, los valores sociales,

\footnotetext{
87 C. J. Thompson, “The Politics of Consumer Identity Work”, en Journal of Consumer Research, vol. 40, no. 5. February 2014, pp. iii-vii, aquí p. iii.

88 J. A. Schumpeter, op. cit., p. 247.

89 J. Gray, op. cit., p. 44.

90 J. Velázquez, op. cit., p. 327.

91 J. Gray, op. cit., p. 61.

92 M. Unamuno, Discursos y conferencias, en Obras Completas, IX, Madrid, Ediciones de la fundación José Antonio de Castro, 2008, P. 839.

93 R. Herrera, Adiós al orden. Una historia sobre la deriva del Estado europeo hasta nuestros días, op. cit., p. 35.

94 A. Badiou, op. cit., pp. 28-29.
} 
obstaculizan la acumulación de capita ${ }^{95}$. Es por esto que las armas para revertir las situaciones de injusticia global se encuentran en el potencial de la multitud para instituir un sabotaje en base a su fuerza productiva ${ }^{96}$; deben rastrearse en el orden mundializado las posibilidades para mejorar la situación presente ya que resulta imposible revertir la situación.

A partir de la administración Reagan, se ha creado en Estados Unidos una intelectualidad independiente, conservadora y, en algunos casos, reaccionaria ${ }^{97}$ que liga su discurso al neoliberalismo y su gestión económica. Se ha construido la imagen de un ser humano autosuficiente en el que la individualidad es llevada al extremo. El resultado es una comunidad narcisista donde lo común es desatendido dejando patente la falta de racionalidad de la política actual ${ }^{98}$. Esta inoperancia se sostiene por una sociedad de consumo indiferenciada y esterilizada por el entretenimiento global ajeno a lo común ${ }^{99}$. La tecnificación representada por la globalización implica la clausura del sistema inmunitario. Este se ultima sobre sí mismo imposibilitando la comprensión de la realidad en forma de rico contraste con la alteridad. Por esta vía, el mundo se estanca en lo óntico al obviar lo ontológico y no se puede remitir a ningún fin trascendente. Lo comunitario pierde su contenido, la política se desvanece y el Estado-nación resulta vapuleado junto a los presupuestos de la modernidad ${ }^{100}$; es por esto que resulta imprescindible el establecimiento de una nueva conceptualización que permita la comprensión del presente y el nuevo orden mundializado. Se transige con la situación, pues, a consecuencia de la concesión masiva de derechos acaecida desde el despegue de los sistemas liberales, se da un alejamiento del rigorismo moral que debiera tutelar lo social ${ }^{101}$.

Lo político, como lo vital, está plagado de contradicciones. Por tanto, la filosofía política está cargada por esta dualidad que representa la lucha entre contrarios. La comunidad, en su forma paradigmática, resulta inefable y su caracterización envuelve una tarea imposible. Ahora bien, la esencialidad del ser humano puede asumirse como incompleta, necesita del otro para consumarse y hacerse efectiva. La conciencia únicamente puede adquirir su forma en esta insuficiencia, en la imposibilidad de ser separado de la comunidad ${ }^{102}$.

El hecho es que quien no trate de ser en los demás, dejará de ser en sí mismo; quien no se esfuerce por imprimir su cuño en los demás, acabará por perderlo. No se conserva y acrecienta espíritu sino dándolo; el que renuncia a influir en los que le rodean y a modificarlos a su imagen y semejanza, renuncia de hecho a conservarse tal cual es $[\ldots]^{103}$.

\footnotetext{
J. Velázquez, op. cit., p. 336.

M. Hardt y A. Negri, op. cit., p. 86.

E. W. Said, op. cit., p. 90.

J. L. Villacañas op. cit., p. 14.

R. Herrera, Adiós al orden. Una historia sobre la deriva del Estado europeo hasta nuestros días, op. cit., p. 191.

100 R. Esposito, Comunidad, inmunidad y biopolítica, op. cit., pp. 92.

101 J. L. Villacañas Berlanga, "Max Weber entre liberalismo y republicanismo", en Isegoría 33, 2005, pp. 127-141, aquí p. 131.

102 M. Blanchot, La comunidad inconfesable, Madrid, Arenas libros, 2002, pp. 17-18.

103 M. Unamuno, Más sobre la crisis del patriotismo, en Obras Completas, VIII, Madrid, Ediciones de la fundación José Antonio de Castro, 2007, p. 904.
} 
Ante el pensamiento impuesto, debe explorarse la búsqueda intelectual de alternativas. Revisar la confianza depositada en los expertos que moldean la opinión pública ${ }^{104} \mathrm{y}$ castran la posibilidad de cambio ${ }^{105}$. En la comunidad es donde se encuentra el lugar idóneo para el desarrollo de la inteligencia y el pensamiento ${ }^{106}$, aunque, claro está, proyectada hacia la nueva globalidad. Sin el enfrentamiento dialéctico entre ideas no se produce el estímulo para la crítica, para la divergencia. En este aspecto, Unamuno entiende el espacio común como indispensable para el impulso de una dimensión cívica asentada en el enfrentamiento intelectual. Solo a partir de esta fractura, del encontronazo entre opuestos, puede surgir una ampliación hermenéutica productora de un sentido alineado con la creación de un horizonte de expectativa. Este es el camino para el cuidado de la política, para el mantenimiento de este elemento frágil y quebradizo ${ }^{107}$. Lo común adquiere sentido como desafío creativo, cuando la crítica y la duda rompen la dogmática social.

Un parlamento sólo es fecundo cuando luchan de veras entre sí los partidos que lo componen, y el nuestro es infecundo porque en él no hay semejante lucha, sino que todos se entienden entre bastidores y salen a las tablas a representar la ridícula comedia de la oposición.

Hay que luchar, y luchar de veras, y buscar sobre la lucha, y merced a ella, la solidaridad que a los combatientes une ${ }^{108}$.

Puesto que todo ser humano está vinculado de manera indefectible al espacio común, tiene que revitalizarse el interés por la política. La politofobia o aversión a lo político se convierte en un rasgo antisocial que atenta contra el civismo: "Con lo que tenemos que procurar acabar todos es con el sentimiento anti-social, insocial por lo menos, que se esconde debajo de aquella frase de: «el Gobierno nada me dá [sic]» ${ }^{109 "}$. En la creatividad poietica, en las posibilidades brindadas por el lenguaje capaz de conceptualizar el tiempo presente se da la ocasión para la transformación. Los retos encubiertos por la globalización deben desvelarse para meditar lo político desde la vida y no, como es la pretensión, suprimir este aspecto indispensable ${ }^{110}$.

Las tendencias actuales, marcadas por la individualidad, no permiten lo político, pues, de esta metafísica de lo absoluto no puede desgajarse lo comunitario ${ }^{111}$. La creación de una posibilidad de futuro solo puede venir por la conceptualización política que no se rinde ante fuerzas abstractas e impersonales ${ }^{112}$. El lenguaje político debe cargarse de sentido, volver a ser un estímulo para la acción práctica. Los momentos de crisis permiten poner en tela de juicio el pasado inmediato para, de forma reflexiva, rastrear nuevas posibilidades. Solo de esta manera cabe la posibilidad de

04 E. W. Said, op. cit., p. 15.

105 Ibidem, p. 18.

106 R. Esposito, Comunidad, inmunidad y biopolitica, op. cit., p. 32.

107 A. Galindo Hervás, Pensamiento impolítico contemporáneo, Madrid, Ediciones sequitur, 2015, p. 55.

108 M. Unamuno, La crisis actual del patriotismo español, en Obras Completas, VIII, Madrid, Ediciones de la fundación José Antonio de Castro, 2007, p. 839.

109 M. Unamuno, Soliloquios y conversaciones, op. cit., p. 350.

110 R. Esposito, Comunidad, inmunidad y biopolítica, op. cit., p. 22.

111 Ibidem, p. 29.

112 M. González García, "Utopía y poder en los orígenes de la modernidad: la utopía como proyecto político y sus críticos” en Moisés González García y Rafael Herrera Guillén (eds.), Utopía y poder en Europa y América, Madrid, Editorial Tecnos, 2015, pp. 95-116, aquí p. 95. 
avance y de emplear este tiempo gozne de un modo adecuado y útil para los intereses humanos. La filosofía, en lugar de centrarse en sistemas políticos, tiene que dirigirse a la producción de conceptos que desbrocen la doble dimensión subyacente en lo aparente ${ }^{113}$. Se necesita del ideal utópico, de la apertura de posibilidades a través de la actividad intelectual creativa. Se impone, en suma, una actitud quijotesca en pugna con lo establecido.

Pero Don Quijote oye ya su propia risa, oye la risa divina, y como no es pesimista, como cree en la vida eterna, tiene que pelear, arremetiendo contra la ortodoxia inquisitorial científica moderna por traer una nueva e imposible Edad Media, dualística, contradictoria, apasionada ${ }^{114}$.

113 R. Esposito, Comunidad, inmunidad y biopolitica, op. cit., p. 138.

114 M. Unamuno, Del sentimiento trágico de la vida en los hombres y en los pueblos, p. 326. 